\title{
AN INVESTIGATION INTO THE LYMPHATIC AND VASCULAR SPREAD OF CARCINOMA OF THE BRONCHUS *
}

BY

\author{
H. C. NOHL \\ From the London Chest Hospital
}

(RECEIVED FOR PUBLICATION JANUARY 28, 1956)

The present investigation was carried out because little work has been done to elucidate the problems concerning the lymphatic spread of bronchogenic carcinoma. The question, whether the treatment of carcinoma of the bronchus by lobectomy rather than by pneumonectomy is based on sound pathological principles, needed clarification. It was also felt that the establishment of a surgical-pathological classification for the purpose of prognosis and assessment of various forms of treatment, as has been done for cancer at other sites, was long overdue. Furthermore, the anatomy of the intrapulmonary lymphatic pathways described in the past are no longer tenable in the light of our present knowledge of the bronchial and segmental anatomy of the lungs.

Rouvière (1932), in his classic Anatomie des Lymphatiques de l'Homme, gives an excellent description of the mediastinal lymphatic pathways and nodes, but that of the interlobar and intrapulmonary nodes is inaccurate and his work does not divide the lymph flow into lobar or segmental distribution. Since that time few contributions have been made in this field; papers by McCort and Robbins (1951), Weinberg (1951), Borrie (1952), and that by Brock and Whytehead (1955) have touched on this subject. But all of these authors, with the exception of Borrie, reiterate, on the whole, Rouvière's statements on either the lymphatic anatomy or the drainage of the lungs.

\section{Method of InVESTigation}

One hundred specimens of lung resected for bronchogenic carcinoma were examined. Of these 71 were pneumonectomies and 29 were lobectomies. They constitute a continuous series, except for three cases which were not investigated, as a growth was not suspected at the time of the operation.

* An enlarged version of a paper read to the Thoracic Society in London in March, 1955.
Each spezimen while still fresh and unfixed was carefully cleared of all the visible lymph nodes, and their relationship to the nearest bronchus was noted and charted on a diagram (Fig. 1).

Vascular involvement was also looked for and pieces of pulmonary vein were sent for histological examination where invasion seemed most likely. Visceral or parietal pleural infiltration was noted and again microscopic confirmation was sought. And, lastly, the situation and extent of the growth were carefully recorded.

Each lymph node was then sectioned after fixation and two slides were made of each gland. A serial section of each lymph node was not done, as it would have entailed an insurmountable amount of work.

In all, 753 lymph nodes were histologically examined, which means an average of 7.5 lymph nodes per specimen. Borrie, who undertook a similar investigation, found five lymph nodes per specimen.

The growth itself was also examined and was described as being one of four types (Table I).

TABLE I

HISTOLOGICAL CLASSIFICATION OF CASES EXAMINED

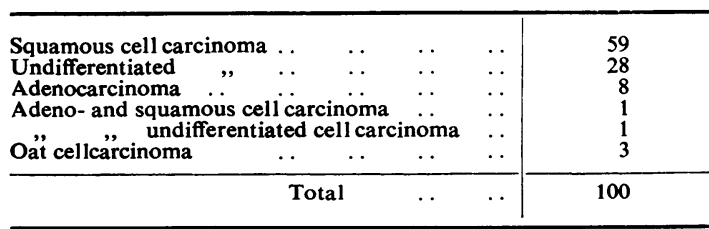

INCIDENCE OF LYMPH NODE INVOLVEMENT

The incidence of lymph node involvement where pneumonectomies had been carried out was $88.8 \%$, while the incidence after lobectomy was only $41.4 \%$. The overall incidence of lymph node involvement in the 100 resected specimens was thus $75 \%$. This percentage is higher than the usual figures quoted (Table II). In this series 7.5 lymph nodes per specimen were found, while in that of Brock and Whytehead, where "radical 

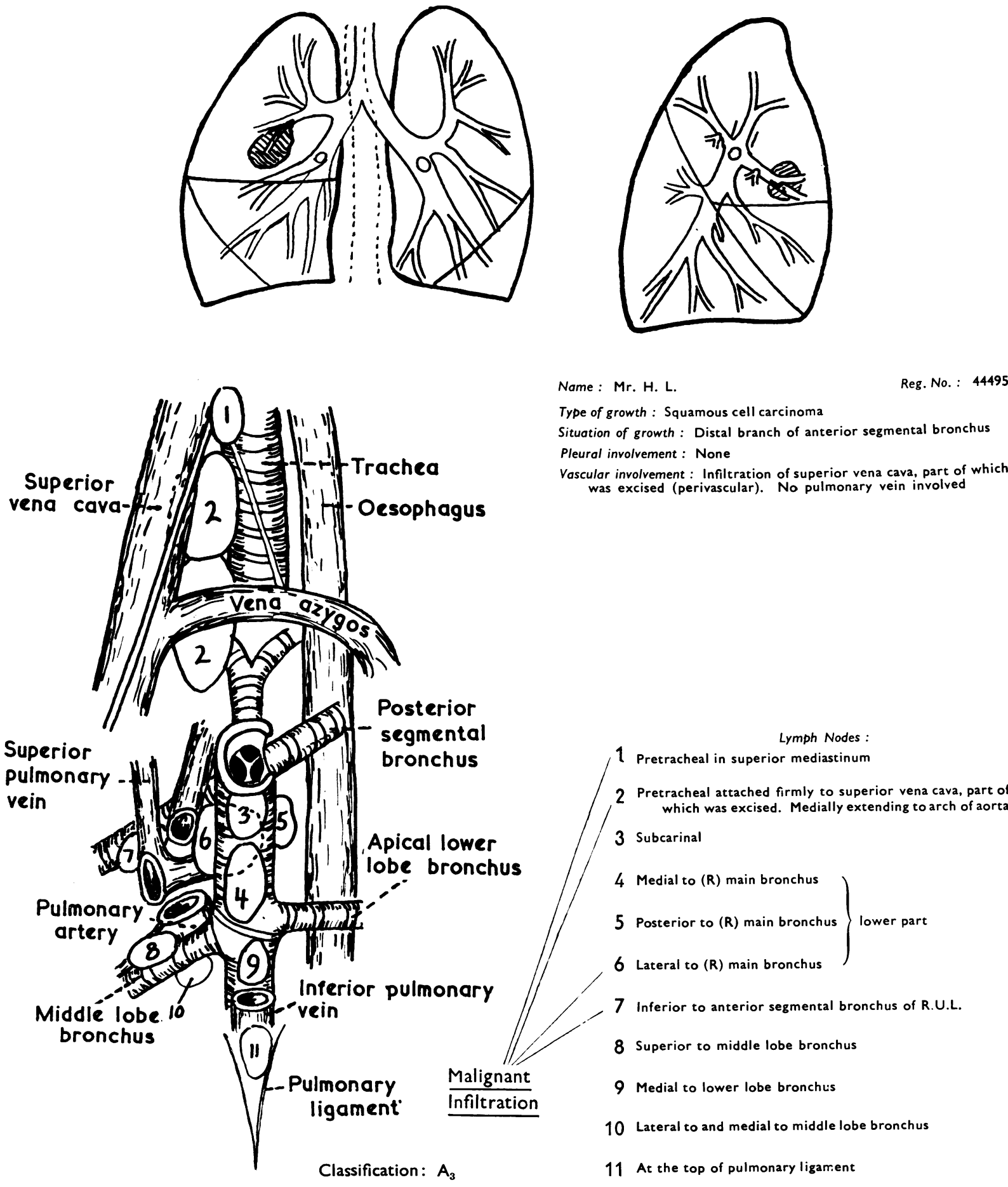

Name: Mr. H. L.

Type of growth : Squamous cell carcinoma

Situation of growth: Distal branch of anterior segmental bronchus

Pleural involvement: None

Vascular involvement : Infiltration of superior vena cava, part of which was excised (perivascular). No pulmonary vein involved

FIG. 1.-Chart which is used to record the site of the nodes dissected and examined histologically. It shows the mediastinal aspect of the resected lung, with the mediastinal structures superimposed. The diagram, therefore, presents the mirror image of the orthodox view. 
TABLE II

INCIDENCE OF LYMPH NODE INVOLVEMENT ACCORDING TO VARIOUS AUTHORS

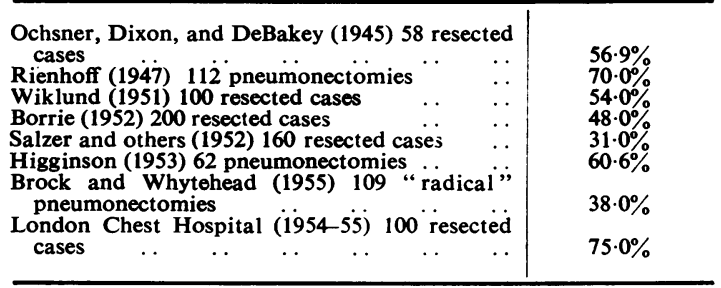

pneumonectomies" were performed, it is stated that 30-40 lymph nodes per specimen were examined, and the percentage of cases showing lymph node involvement was $38 \%$ in the 109 cases where the state of glands is mentioned. In necropsy series the incidence is, of course, very much higher and ranges from $75 \%$ (Simpson, 1929) to $94 \%$ (Willis, 1953). It was often difficult to forecast from macroscopic appearances whether a lymph node was malignant or not. Often large firm nodes were free from growth, while small, innocent-looking ones showed a secondary. Microscopic metastases are most likely to be found under the capsule of the node where the afferent lymphatic vessels open into the peripheral sinuses.

The Macroscopic anatomy of the Lymphatic Pathways of the Lungs as Demonstrated by

\section{LYMPHATIC METASTASES}

As previously stated, not much research has been done in recent years on the lymphatic pathways by which metastases from growths in various segments and lobes spread towards the hilar and mediastinal lymph nodes. For this reason the conclusions drawn from the dissections done on the 100 cases in this series are described in this section. However, in view of the fact that in the majority of cases the growth has involved more than one segment, it is only possible to describe the lobar drainage with definite certainty.

Right Lung.-There was a total of 47 rightsided growths.

Of these 19 growths were involving the upper lobe

\begin{tabular}{|c|c|c|c|}
\hline 18 growths & ", & " & "lower lobe \\
\hline 2 growths & $"$ & " & $=\underset{\text { middle }}{\text { lobe }}$ \\
\hline 5 growths & ", & ", & $" \begin{array}{l}\text { upper and } \\
\text { lower lobes }\end{array}$ \\
\hline 2 growths & ", & ", & $\begin{array}{l}\text { middle and } \\
\text { lower lobes }\end{array}$ \\
\hline & " & ", & " upper and \\
\hline
\end{tabular}

Table III shows the location of the various lymph nodes on the right side of the chest and also indicates the site of the growth of each particular lymph node.

Figs. 2 and 3 indicate diagrammatically the anatomical position of the more important lymph nodes.

Three hundred and forty-seven lymph nodes were examined, of which 108 showed metastatic deposits, giving an invasion rate of $31 \%$. (The invasion rates for the various lobes are given in Table V.)

On analysing Table III the following features become apparent.

TABLE III

LYMPH NODES OF THE RIGHT LUNG

\begin{tabular}{|c|c|c|c|c|c|c|c|}
\hline \multirow[b]{2}{*}{ Site of Lymph Nodes } & & \multicolumn{6}{|c|}{ Site of Growth } \\
\hline & & 离: & 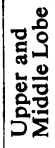 & 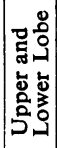 & 过 & 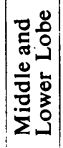 & 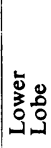 \\
\hline $\begin{array}{l}\text { Mediastinal } \\
\text { Pre-, para-, or retro- } \\
\text { tracheal } \\
\text { Subcarinal . . } \\
\text { Para-oesophageal . } \\
\text { Pericardial or para- } \\
\text { phrenic } \\
\text { In relation to upper part } \\
\text { of right main bronchus } \\
\begin{array}{l}\text { In relation to upper lobe } \\
\text { bronchus }\end{array} \\
\text { In relation to upper lobe } \\
\text { segmental bronchi }\end{array}$ & $\begin{array}{l}\text { Not invaded } \\
\text { Invaded } \\
\text { Not invaded } \\
\text { Invaded } \\
\text { Not invaded } \\
\text { Invaded } \\
\text { Not invaded } \\
\text { Invaded } \\
\text { Not invaded } \\
\text { Invaded } \\
\text { Not invaded } \\
\text { Invaded } \\
\text { Not invaded } \\
\text { Invaded }\end{array}$ & $\begin{array}{r}7 \\
9 \\
10 \\
1 \\
2 \\
1 \\
1 \\
1 \\
10 \\
2 \\
5 \\
1 \\
8 \\
6\end{array}$ & $\begin{array}{l}1 \\
1\end{array}$ & $\begin{array}{l}1 \\
1 \\
1\end{array}$ & 1 & $\begin{array}{l}1 \\
1 \\
2 \\
1 \\
1 \\
1\end{array}$ & $\begin{array}{r}3 \\
3 \\
6 \\
6 \\
4 \\
3 \\
3 \\
1 \\
4 \\
2 \\
6 \\
1 \\
11 \\
1 \\
\end{array}$ \\
\hline $\begin{array}{l}\text { In relation to lower part } \\
\text { of right main bronchus }\end{array}$ & $\begin{array}{l}\text { Not invaded } \\
\text { Invaded }\end{array}$ & $\begin{array}{l}25 \\
10\end{array}$ & 2 & $\begin{array}{l}4 \\
3 \\
\end{array}$ & $\begin{array}{l}3 \\
2 \\
\end{array}$ & $\begin{array}{l}1 \\
2\end{array}$ & $\begin{array}{l}25 \\
14 \\
\end{array}$ \\
\hline $\begin{array}{l}\text { In relation to middle lobe } \\
\text { bronchus } \\
\text { In relat ion to lower lobe } \\
\text { bronchus and segmen- } \\
\text { tal branches } \\
\text { Pulmonary ligament .. }\end{array}$ & $\begin{array}{l}\text { Not invaded } \\
\text { Invaded } \\
\text { Not invaded } \\
\text { Invaded } \\
\text { Not invaded } \\
\text { Invaded }\end{array}$ & $\begin{array}{r}15 \\
1 \\
13 \\
1 \\
2\end{array}$ & 1 & $\begin{array}{l}2 \\
1 \\
1 \\
3\end{array}$ & $\begin{array}{l}2 \\
4 \\
3\end{array}$ & 1 & $\begin{array}{r}17 \\
6 \\
13 \\
7\end{array}$ \\
\hline
\end{tabular}

Total, 347. Invaded, 108. Invasion rate, $31 \%$.

Lower lobe growths metastasize upwards, even occasionally into the lymph nodes around the segmental bronchi of the upper lobe. The subcarinal and the para-oesophageal glands are often involved, while this seems to be a very infrequent event with upper lobe growths.

The most important lymph nodes from the surgical point of view seem to be those in relation to the lower part of the right main bronchus, i.e., the area which lies between the upper lobe bronchus and the middle and apical lower lobe bronchi. This area was referred to by Borrie in his Hunterian Lecture as the "lymphatic sump" of the right lung. It is indicated in Fig. 2 by a circle, 


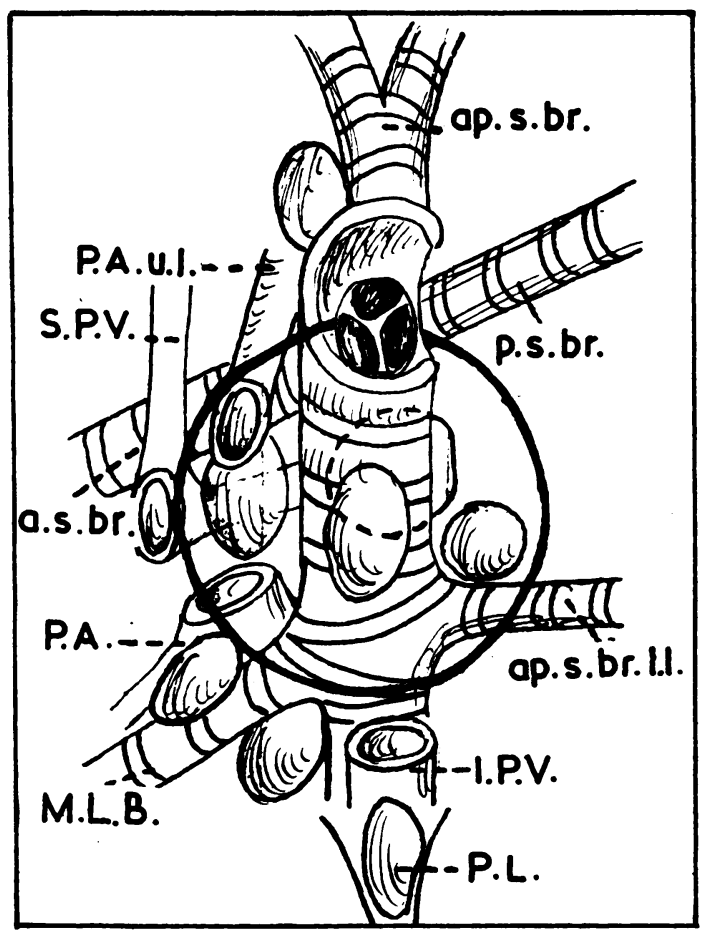

Fig. 2.-Diagram showing the mediastinal aspect of the resected right lung. The circle indicates the area which contains those lymph nodes into which both upper, middle, and lower lobes drain.

while the lymph nodes pertaining to this area are shown between the two double lines in Table III.

The collection of lymph nodes in this region is frequently infiltrated from both upper and lower lobe growths. This seems to have a bearing on treatment of carcinoma by lobectomy. A carcinoma in the lower lobe, however small and peripheral, should, according to these observations, be treated by at least a lower and middle lobectomy. It is also essential to remove the tissues most likely to contain the para-oesophageal, the subcarinal nodes, and those in the pulmonary ligament. Churchill, Sweet, Soutter, and Scannell (1950) seem to have included a middle lobectomy for a growth confined to the lower lobe on occasions. On the other hand obviously malignant nodes in this area will make a lobectomy technically impossible.

Upper lobe growths also metastasize to the lymph nodes between the upper lobe bronchus and the middle and apical lower lobe bronchus. They do not, however, infiltrate the nodes below a line drawn from the middle lobe bronchus to the apical lower lobe bronchus. The exception to this rule are those upper lobe tumours which have transgressed the main fissure. However, there was ap.s.br.= apical segmental bronchus

ap.s.br.I.l. = apical segmental bronchus of lower lobe

a.s.br. = anterior segmental bronchus

I.P.V. = inferior pulmonary vein

M.L.B. = middle lobe bronchus

P.A. = pulmonary artery

P.A.u.l.= pulmonary artery to upper lobe

P.L. = pulmonary ligament

S.P.V.= superior pulmonary vein

Oes. $=$ oesophagus

Tr. = trachea

p.s.br. = posterior segmental bronchus

S.V.C. = superior vena cava

Lymph Nodes:

(I) Paraphrenic

(2) Subcarinal

(3) Para-oesophageal

(4) Paratracheal

(5) Pretracheal

(6) Retrotracheal

(7) Pulmonary ligament

one case which contradicts this observation, and one must assume that malignant obstruction of the lymph channels caused a retrograde spread.

The lymphatic drainage with upper lobe growths seems otherwise to be upwards, with the likelihood of involvement of the para- and pretracheal glands.

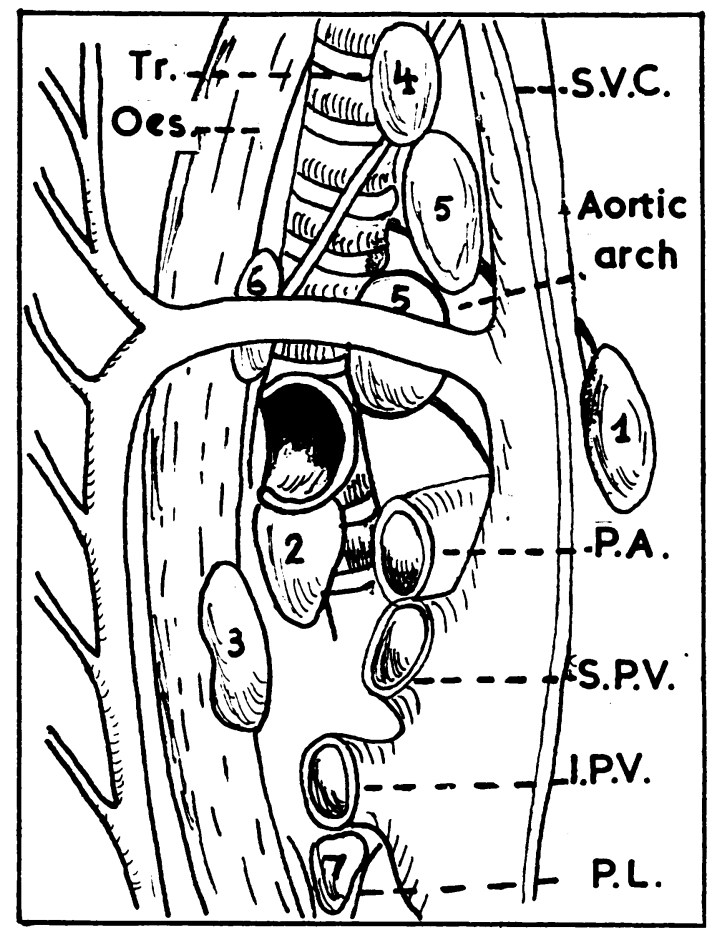

FIG. 3.-Diagram demonstrating the site of the most frequently found lymph nodes in the right mediastinum. 

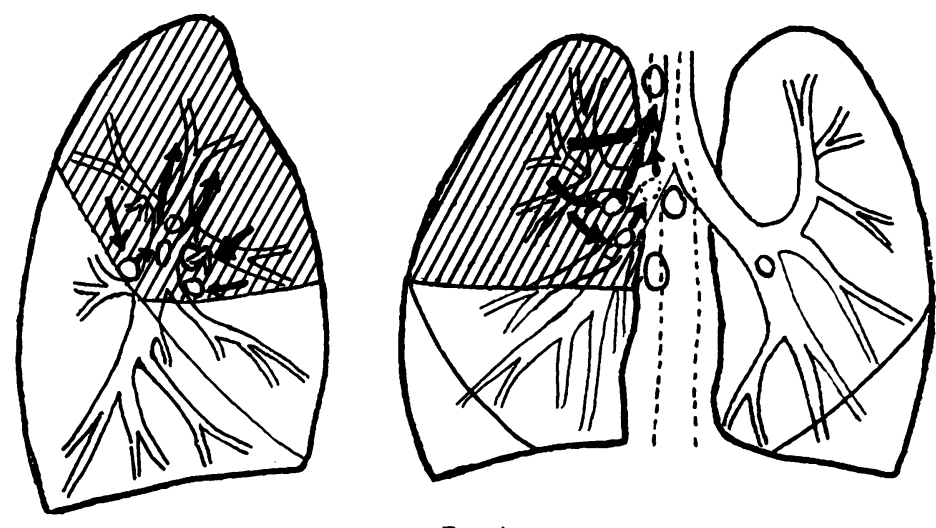

FIG. $4 a$
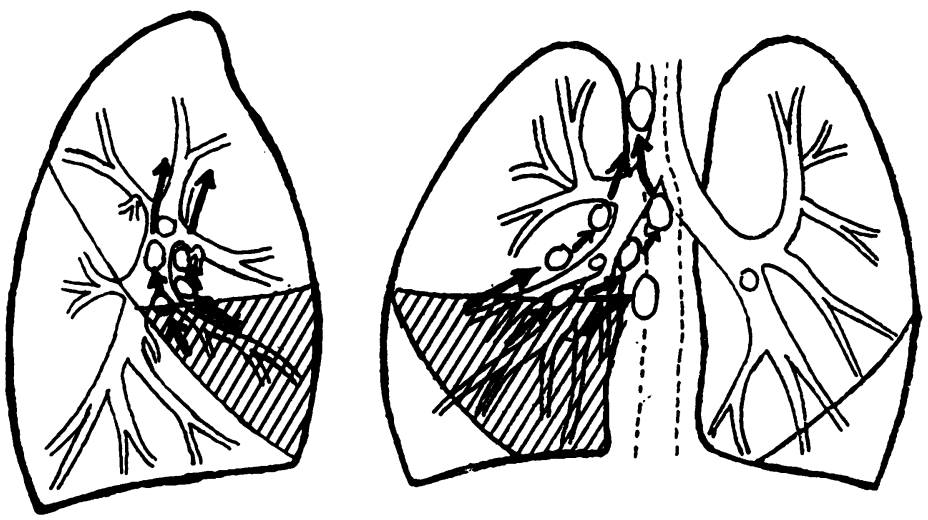

Fig. $4 b$
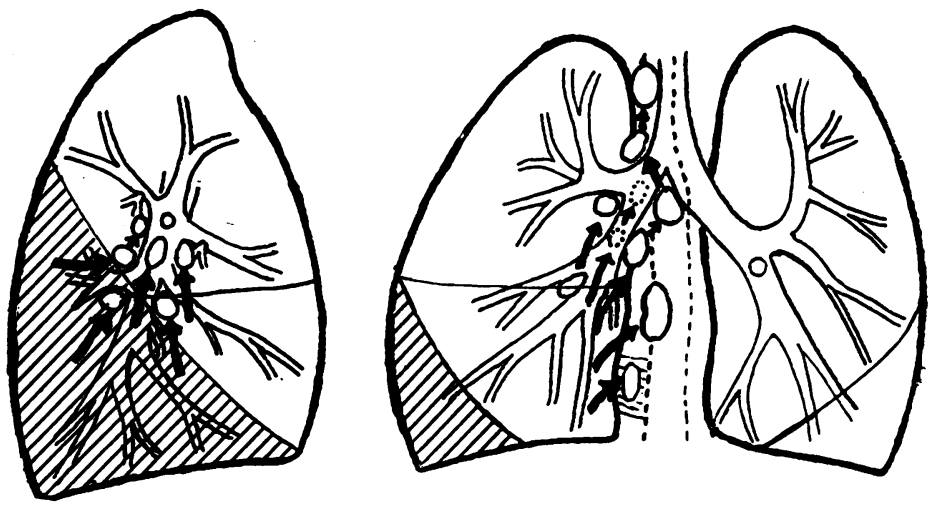

Fro. 4c

Frg. 4.-This diagram illustrates the lymphatic drainage of the three lobes of the right lung. (4a) Upper lobe, (4b) middle lobe, (4c) lower lobe. 


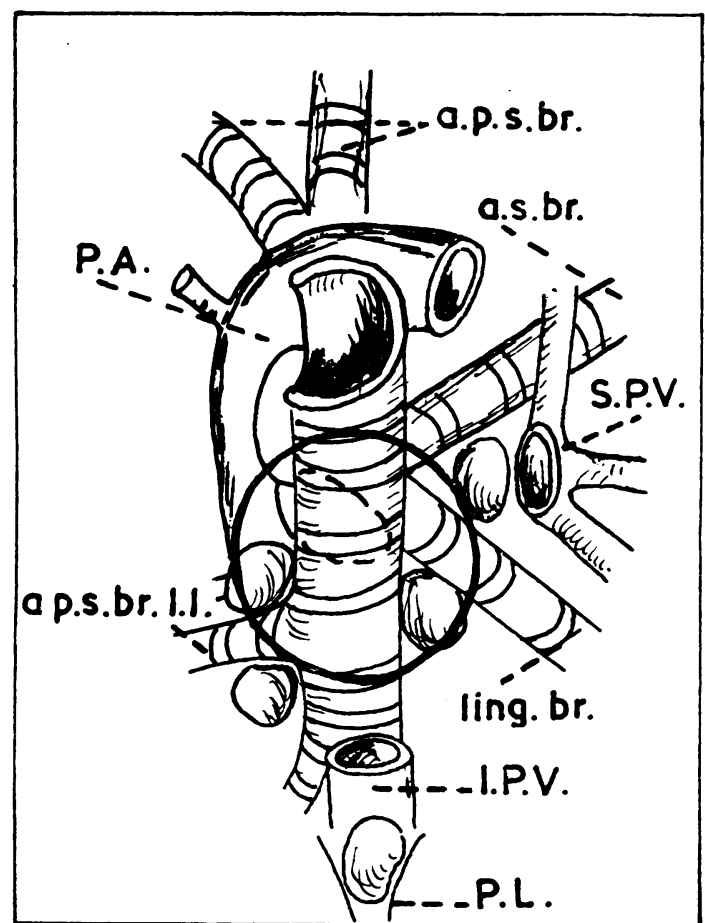

FIG. 5.-Diagram showing the mediastinal aspect of the resected left lung. The circle indicates the region which contains the collection of lymph nodes to which both upper and lower lobes drain.

Infiltration of the subcarinal nodes by upper lobe tumours, on the other hand, is very rare. This means that an upper lobectomy is by itself an inadequate operation where lymphatic clearance is concerned. It should be combined with the division of the vena azygos and clearance of the lymph nodes around the trachea and, if technically feasible, removal of all the glands around the pulmonary artery between the upper and apical lower lobe bronchi. Fig. 4 summarizes these points.

The anatomy of the mediastinal lymph nodes on both sides of the chest (Figs. 3 and 6) is so well described by Rouvière that no further description of them need be given here. It suffices to say that what here are described as the para-oesophageal glands are those of the posterior mediastinum in his nomenclature, the subcarinal nodes are the inter-tracheobronchial nodes, while the paraphrenic nodes are those which belong to the anterior or prevascular chain in his terminology. Brock and Whytehead (1955) describe in addition an anterior tracheal group which lies in front of the lowest part of the trachea and the right main a.p.s.br.= apico-posterior segmental bronchus ap.s.br.I.I.=apical segmental bronchus lower lobe a.s.br. $=$ anterior segmental bronchus

I.P.V. = inferior pulmonary vein

ling.br. = lingular bronchus

P.A. = pulmonary artery

P.L. = pulmonary ligament

S.P.V.= superior pulmonary vein

Oes. $=$ oesophagus

Tr. $=$ trachea

Lymph Nodes:

(I) Subcarinal

(2) Para-oesophageal

(3) Pulmonary ligament

(4) Paraphrenic

(5) Subaortic in region of recurrent laryngeal r.erve

(6) Subaortic in region of ligamentum arteriosum

(7) Para-aortic

(8) Superior mediastinum

bronchus. This group really constitutes the bridge of lymphatic tissue between the subcarinal and the right lateral or paratracheal nodes.

LeFT LUNG.-Table IV and Figs. 5 and 6 represent the conditions found on the left side of the chest.

On this side 405 lymph nodes were found, of which 114 showed malignant invasion, which

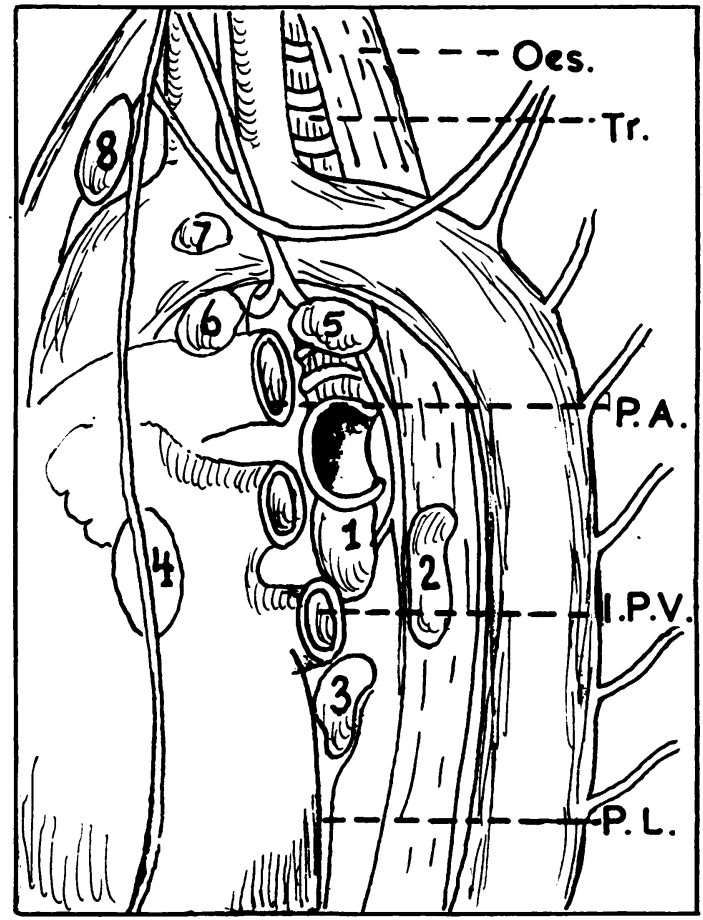

FIG. 6.-Diagram demonstrating the site of the most frequently found lymph nodes in the left mediastinum. 
TABLE IV

LYMPH NODES OF THE LEFT LUNG

\begin{tabular}{|c|c|c|c|c|}
\hline \multirow[b]{2}{*}{ Site of Lymph Nodes } & & \multicolumn{3}{|c|}{ Site of Growth } \\
\hline & & $\begin{array}{l}\text { Upper } \\
\text { Lobe }\end{array}$ & $\begin{array}{l}\text { Upper } \\
\text { and } \\
\text { Lower } \\
\text { Lobe }\end{array}$ & $\begin{array}{l}\text { Lower } \\
\text { Lobe }\end{array}$ \\
\hline $\begin{array}{l}\text { Mediastinal } \\
\text { In anterior superior media- } \\
\text { stinum or para-aortic } \ldots \\
\text { Subaortic }\left\{\begin{array}{r}\text { (a) Rec. laryng. } \\
\text { nerve } \\
\text { (b) Ligamentum } \\
\text { arteriosum }\end{array}\right.\end{array}$ & $\begin{array}{l}\text { Not invaded } \\
\text { Invaded } \\
\text { Not invaded } \\
\text { Invaded }\end{array}$ & $\begin{array}{l}4 \\
1\end{array}$ & 7 & 13 \\
\hline Subcarinal $\quad \ldots \quad \ldots$ & $\begin{array}{l}\text { Not invaded } \\
\text { Invaded }\end{array}$ & $\begin{array}{l}3 \\
9 \\
3\end{array}$ & $\begin{array}{l}3 \\
4 \\
1\end{array}$ & $\begin{array}{l}2 \\
1 \\
3\end{array}$ \\
\hline Para-oesophageal $\quad . . \quad$.. & $\begin{array}{l}\text { Not invaded } \\
\text { Invaded }\end{array}$ & $\begin{array}{l}3 \\
2\end{array}$ & & $\begin{array}{l}4 \\
1\end{array}$ \\
\hline Pre- or paratracheal $\quad$. & $\begin{array}{l}\text { Not invaded } \\
\text { Invaded }\end{array}$ & 1 & & \\
\hline Pericardial or paraphrenic .. & $\begin{array}{l}\text { Not invaded } \\
\text { Invaded }\end{array}$ & $\begin{array}{l}6 \\
3\end{array}$ & 1 & \\
\hline $\begin{array}{lll}\text { Parietal pleura } & \ldots & \ldots\end{array}$ & $\begin{array}{l}\text { Not invaded } \\
\text { Invaded }\end{array}$ & 3 & 1 & \\
\hline In relation to upper lobe bronchus & $\begin{array}{l}\text { Not invaded } \\
\text { Invaded }\end{array}$ & $\begin{array}{r}19 \\
8\end{array}$ & 1 & $\begin{array}{l}5 \\
1\end{array}$ \\
\hline $\begin{array}{l}\text { In relation to upper lobe segmen- } \\
\text { tal bronchi } \\
\text { Left main stem bronchus }\end{array}$ & $\begin{array}{l}\text { Not invaded } \\
\text { Invaded } \\
\text { Not invaded } \\
\text { Invaded }\end{array}$ & $\begin{array}{r}30 \\
14 \\
18 \\
8\end{array}$ & $\begin{array}{l}2 \\
7 \\
8 \\
2 \\
\end{array}$ & $\begin{array}{r}13 \\
2 \\
5 \\
4 \\
\end{array}$ \\
\hline $\begin{array}{l}\text { Between upper and lower lobe } \\
\text { bronchus }\end{array}$ & $\begin{array}{l}\text { Not invaded } \\
\text { Invaded }\end{array}$ & $\begin{array}{r}32 \\
7 \\
\end{array}$ & $\begin{array}{l}3 \\
5 \\
\end{array}$ & $\begin{array}{l}1 \\
14 \\
\end{array}$ \\
\hline $\begin{array}{l}\text { In relation to lower lobe bronchus } \\
\text { and segmental branches } \\
\text { Pulmonary ligament } \quad .\end{array}$ & $\begin{array}{l}\text { Not invaded } \\
\text { Invaded } \\
\text { Not invaded } \\
\text { Invaded }\end{array}$ & $\begin{array}{r}13 \\
1 \\
9\end{array}$ & $\begin{array}{l}3 \\
5 \\
6 \\
1\end{array}$ & $\begin{array}{r}14 \\
3 \\
12 \\
3\end{array}$ \\
\hline
\end{tabular}

Total, 405. Invaded, 114. Invasion rate, $28 \cdot 1 \%$.

means an invasion rate of $28.1 \%$ as compared with $31 \%$ on the right side of the chest.

There was a total of 53 left-sided growths.

Of these 28 growths were involving the upper lobe

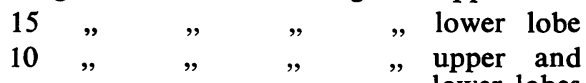
lower lobes

On this side more lower lobe carcinomata invaded also the upper lobe than on the right side. The nodes around the upper lobe bronchus and its segmental branches often show metastases from such neoplasms.

The noteworthy features on this side were as follows. There was only one paratracheal and one para-aortic node invaded. In both of these cases the advanced upper lobe growth gave rise to extensive lymphatic invasion, and both patients died within four months of the operation. This seems to confirm the general opinion that on the left side few growths drain upwards alongside the trachea. Unlike the right side, upper lobe carcinomata have given rise to metastases in the subcarinal gland. It may be that here the lymphatic drainage crosses over to the other side to continue upwards in the right superior mediastinum. Radiological appearances in advanced cases often show this contralateral spread. Warren and
Drinker (1942) demonstrated in dogs that the greater portion of the total pulmonary lymphatic flow passes up into the right paratracheal chain, while only a small amount from the left upper lobe drains upwards in the left superior mediastinum. Weinberg (1951), who has been investigating the lymphatic flow by vital staining, using a $4 \%$ solution of Pontamine sky blue at the time of operation, noticed staining of the nodes in the opposite hemithorax in two cases in which death occurred 11 days after pulmonary resection. The cross-staining had been carried through the subcarinal and anterior mediastinal lymph nodes. It must also be remembered that the right para- and pretracheal nodes medial to the vena azygos do extend on occasions as far over to the left as the arch of the aorta (see Fig. 3) and are thus in close proximity to the subaortic glands. Fig. 7 demonstrates a metastasis in a right "scalene node," while the primary is situated in the left upper lobe.

The important area from the surgical point of view on the left side is the collection of lymph nodes lying between the upper and lower lobe bronchus in the main fissure. This constitutes the "lymphatic sump," to use Borrie's phrase, on the left side. It is indicated by a circle in Fig. 5 and lies between the bold rules in Table IV. The lymph node situated above the apical lower lobe segmental bronchus and the node lying along the inferior border of the lingular bronchus belong to this group. These nodes frequently showed malignant infiltration from both upper and lower lobe growths. As on the right side, except for one instance, no upper lobe growth metastasized below this level.

The nodes below the aortic arch in the region of the recurrent laryngeal nerve and the ligamentum arteriosum were nearly always present, and involvement was in the majority of cases caused by upper lobe tumours. It is invasion of these nodes which causes recurrent laryngeal nerve paralysis in the more advanced cases.

The other interesting finding was the frequent invasion of the node situated between the anterior segmental bronchus and the lingular bronchus of the upper lobe in close proximity to the superior pulmonary vein. It was this node which was frequently invading this vessel, necessitating intrapericardial ligation at the time of operation.

To sum up, the lymphatic spread on the left side (Fig. 8): Left lower lobe growths metastasize upwards, with frequent involvement of the node above the apical lower lobe bronchus. The paraoesophageal and the nodes in the pulmonary ligament are liable to be invaded. The glands around 

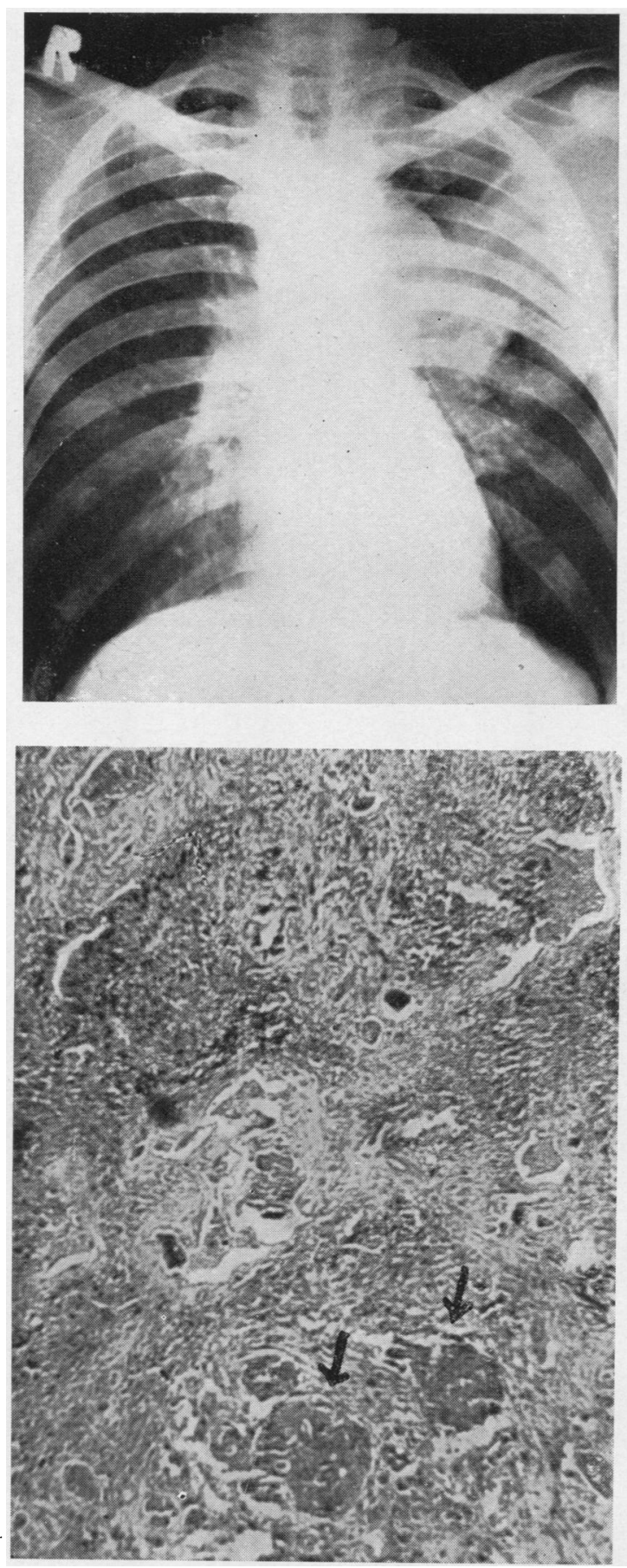

FIG. 7.-The radiograph of a patient with a left upper lobe carcinoma. Section of one of the lymph nodes overlying the right scalenus anterior muscle in the same patient shows islands of malignant tissue (arrows). the left main bronchus and the subcarinal nodes are also likely to be involved. Lower lobe tumours often transgress the main fissure. Such growths tend to metastasize also to the nodes in relation to the upper lobe bronchus and its segmental branches and the subaortic glands.

Left upper lobe growths similarly give rise to secondaries in the node in the main fissure above the apical lower lobe bronchus and in the node lying along the inferior border of the lingular bronchus. They do not, however, infiltrate nodes below this level. The nodes around the left main bronchus are often involved. The subaortic nodes are liable to invasion and so are the subcarinal glands. Upward spread in the left superior mediastinum, on the other hand, seems to be rare.

In conclusion upper and lower lobectomy on the left side, where technically feasible, should achieve a reasonably adequate lymphatic clearance.

\section{Comparison of InVasion Rates Between the DifFERENT LOBES}

From Table $\mathrm{V}$ it will be seen that the lower lobes carry a slightly higher invasion rate than the upper lobes. The cases where the middle lobe

TABLE V

INVASION RATES OF UPPER AND LOWER LOBES COMPARED

\begin{tabular}{|c|c|c|c|c|}
\hline Site of Growth & $\begin{array}{l}\text { No. of } \\
\text { Cases }\end{array}$ & $\begin{array}{l}\text { Nodes } \\
\text { Present }\end{array}$ & $\begin{array}{c}\text { Nodes } \\
\text { Invaded }\end{array}$ & $\begin{array}{l}\text { Invasion } \\
\text { Rate (\%) }\end{array}$ \\
\hline $\begin{array}{l}\text { Right upper lobe } \\
\text { Right upper and lower }\end{array}$ & 19 & 135 & 33 & 24.4 \\
\hline $\begin{array}{l}\text { lobe } \\
\text { Right lower lobe } \\
\text { Left upper lobe } \\
\text { Left upper and lower lobe } \\
\text { Left lower lobe }\end{array}$ & $\begin{array}{r}5 \\
18 \\
28 \\
10 \\
15\end{array}$ & $\begin{array}{r}32 \\
143 \\
230 \\
64 \\
111\end{array}$ & $\begin{array}{l}11 \\
47 \\
53 \\
28 \\
33\end{array}$ & $\begin{array}{l}33 \cdot 8 \\
32 \cdot 8 \\
23 \\
43 \cdot 8 \\
29 \cdot 7\end{array}$ \\
\hline
\end{tabular}

was involved either alone or together with one of the adjacent lobes have been left out as the numbers are too small.

Bignall and Moon (1955) in their large series of resected cases came to the conclusion that the left lower lobe carries the worst prognosis. This fact could be explained by the findings of this investigation. The invasion rate of the right lower lobe is slightly higher than that of the left lower lobe. This finding agrees with Borrie's similar investigation. The lower lobe growths on the left side, however, have a frequent tendency to transgress the main fissure, 10 cases compared with five on the right. When this occurs the invasion rate goes up to $43.8 \%$. Furthermore a resection on the left side cannot possibly deal with an unnoticed lymphatic spread to the opposite superior mediastinum. 

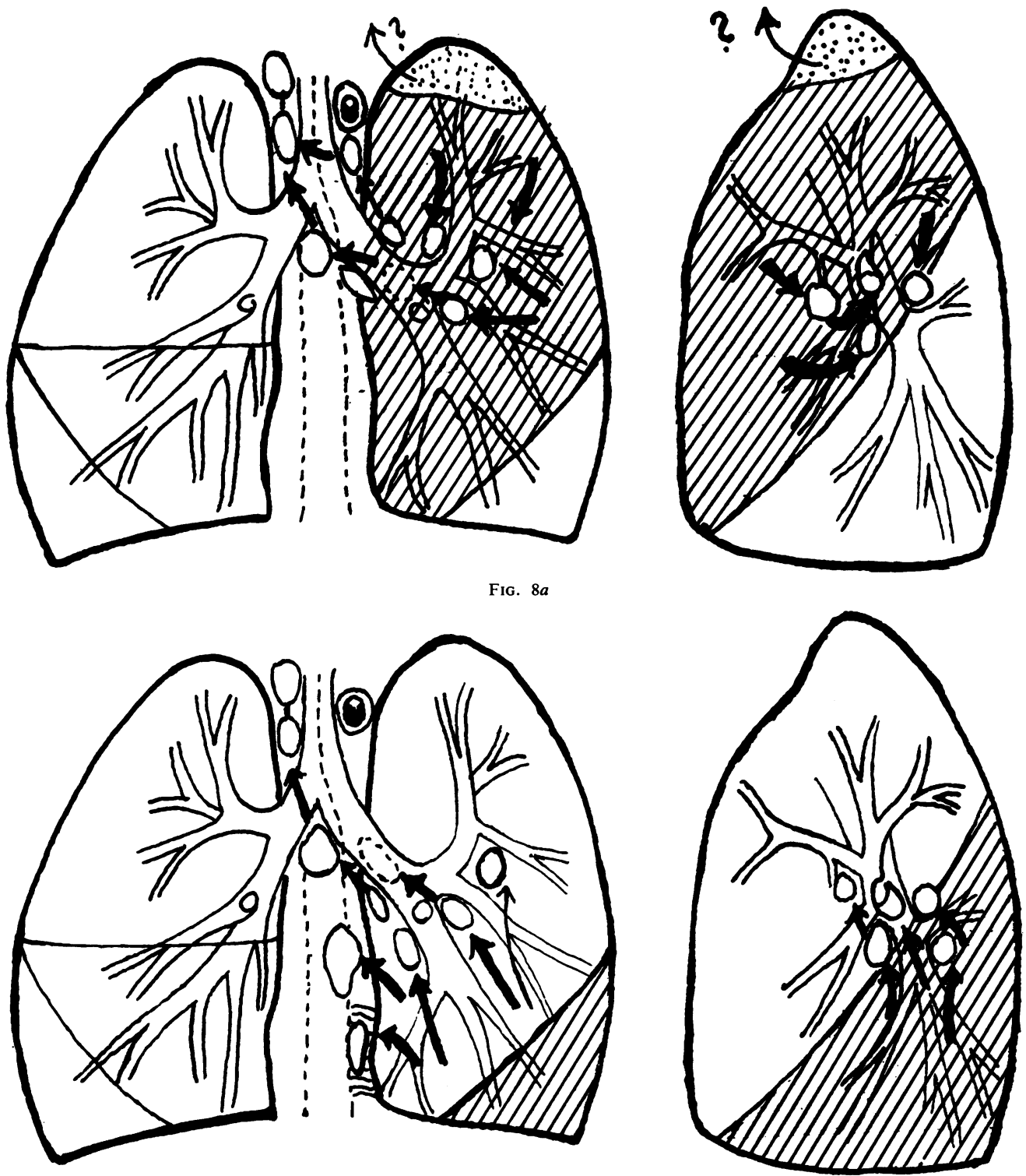

Fig. $8 b$

Fig. 8.-This diagram illustrates the lymphatic drainage of the two lobes of the left lung. (8a) Upper lobe, (8b) lower lobe.

The Bronchial and Vascular Spread of BRONCHOGENIC CARCINOMA

Peribronchial Spread.-During these dissections it was observed that some very advanced growths had started at the periphery of the lung and were involving the parenchyma extensively towards the hilum. There were widespread lymphatic metastases in these cases. The lumen of the bronchi showed no growth; they were narrowed but not invaded. The pre-operative $\omega$ bronchoscopy was therefore negative in spite of 2 the advanced state of affairs. In these cases wide- $\bullet$ spread peribronchial lymphatic invasion had occurred.

INTRABRONCHIAL SPREAD.-The opposite finding was extensive invasion of the submucous lymph $\mathbb{\mathbb { D }}$ channels, so that the growth appeared to creep $\frac{\Omega}{\mathbb{D}}$ up the bronchus within its lumen only. In two 


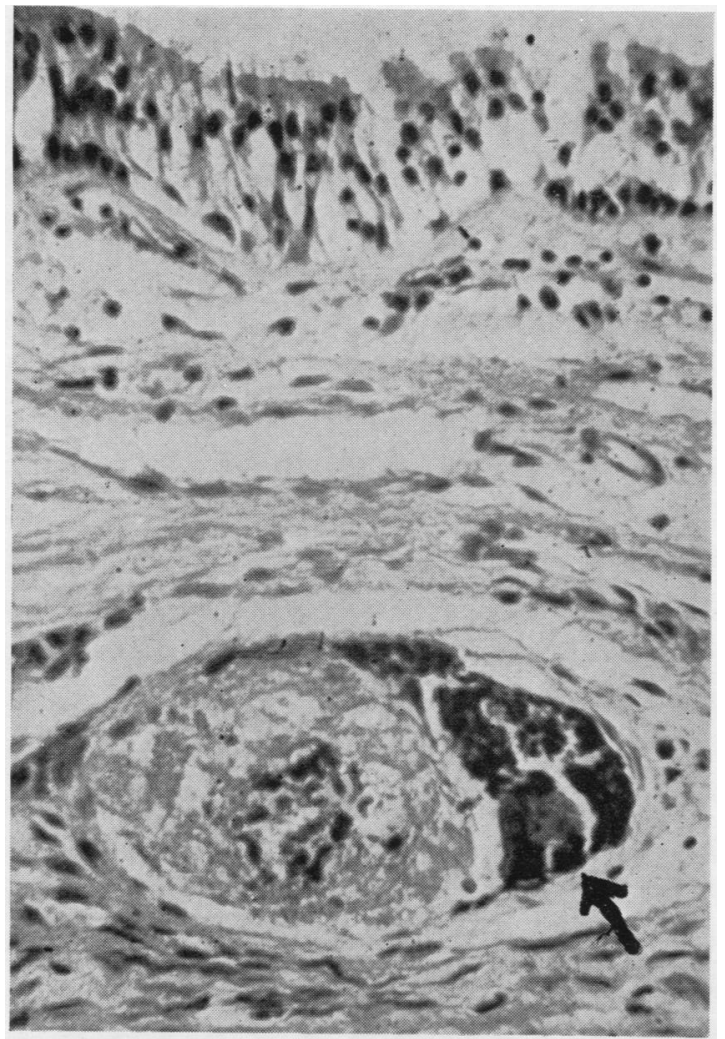

Fig. 9.-Section obtained by bronchial biopsy. A submucous lymphatic vessel can be seen containing malignant cells (arrow), while the bronchial mucosa shows normal ciliated epithelium.

cases an upper lobe growth was seen to advance over the carina between the upper and the lower lobe, down into the lower lobe bronchus, blocking the apical lower lobe bronchus. In these instances the lower lobe was otherwise free from growth. In a third patient, who did not come to operation, the growth had crept from the left main bronchus over the carina into the right main bronchus, as seen through the bronchoscope. Fig. 9 is the actual bronchial biopsy of this patient and shows the infiltration of the submucous lymphatic vessels.

The growth progresses in these cases within the lumen by finally breaking through the mucosa. The lymphatic involvement will therefore always be more proximal than the actual growth as seen by the bronchoscopist. Any growth on the medial wall of the two main bronchi within 1 to $2 \mathrm{~cm}$. of the carina must therefore be deemed inoperable.

VAscular Spread.-It was surprising to find how relatively infrequently the larger vessels were infiltrated by growth. The vessels can be traced far into the tumour, being only cuffed, but not actually showing intimal invasion. Histological sections in these cases show infiltration of the perivascular lymphatics, running in the adventitia of the vessel (Fig. 10). This makes it seem likely that malignant emboli arise more often in the smaller and thinner-walled vessels at the periphery of the lung (Fig. 11).

Aylwin (1951) found intimal invasion in $40 \%$ of cases on examining the slides made from previous resections. But he states that a figure nearer to $60 \%$ can be reached by careful dissection. The incidence of vascular involvement in this series was only $30 \%$.

\section{A Surgical-Pathological Classification}

It was felt that a classification, such as has been so successfully established for cancer at other sites, was urgently needed for carcinoma of the bronchus. If any form of treatment of this disease is to be compared with any other therapeutic methods, it is essential to employ some scheme by which the extent of the growth and the lymphatic and vascular involvement are recorded. Even comparison of operative mortality and survival figures between various published

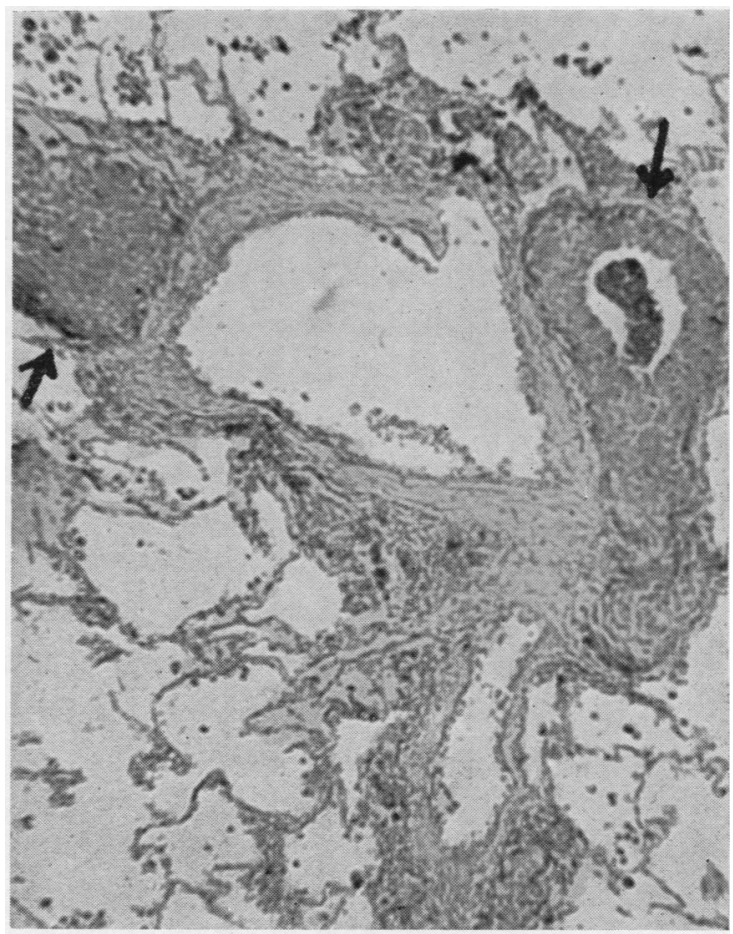

FIG. 10.-Section showing malignant infiltration of the perivascular lymphatic vessels of a small peripheral blood vessel (arrows). 
series seems meaningless without such grading. Whether with the aid of such a classification a prognosis can be given can only be ascertained after a lapse of time.

\section{Salzer's Classification of Carcinoma of the BRONCHUS (1951) MODIFIED}

Salzer (1951) proposed such a classification:

A Cases: Growth confined to the lung.

B Cases: The tumour has reached the visceral pleura, but has not infiltrated it.

$C$ Cases: The growth has infiltrated by continuity the neighbouring structures, e.g., chest wall, pericardium, oesophagus, etc.

Lymph Node Involvement

$0=$ No lymphatic metastases.

$1=$ Infiltration of the intrapulmonary nodes has occurred.

$2=$ The interlobar or hilar nodes are metastasized.

$3=$ The mediastinal nodes show invasion.

$4=$ Distal metastases are present, e.g., supraclavicular nodes, liver metastases, etc.

Vascular Involvement

$\mathrm{V}=$ There is demonstrable invasion of the intima of the pulmonary veins.

This scheme was adopted in this series with only slight modifications. Salzer classifies a case into the B category when the growth encroaches on to

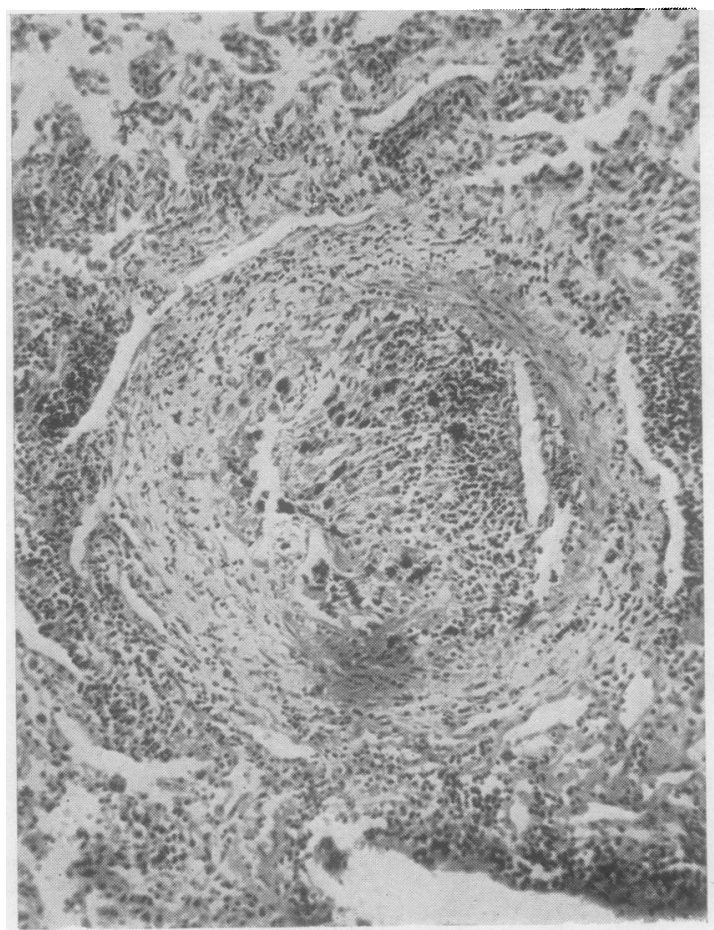

Fig. 11.-A malignant thrombus can be seen within the lumen of a small blood vessel.

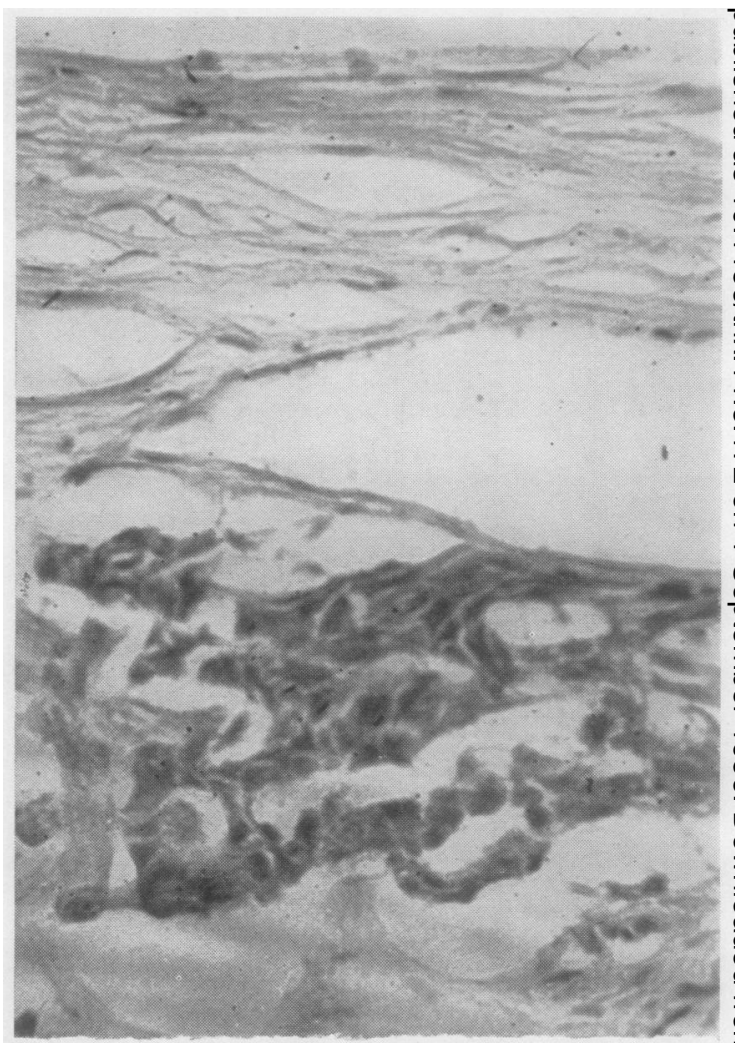

Fig. 12.-This section demonstrates malignant infiltration of the subpleural plextis of lymphatic vessels.

the visceral pleura without infiltrating it. There must be adhesions over this area obliterating the pleural space. He makes this latter point because of the likelihood of lymphatic spread across the adhesions to the chest wall. It was thought that the presence of adhesions was not essential to classify a case into the B category. The risk of infiltration of the subpleural plexus seemed to be sufficient to distinguish such a case from an A case (Fig. 12). There will then be the added risk of pleural metastases and spread across the fissures via lymphatic channels which Ninfo (1950) has been able to demonstrate.

The other modification deemed necessary was the introduction of an extra category indicating confirmed vascular involvement, as this makes the prognosis obviously worse. Such cases are designated as $\mathrm{V}$ cases.

Fig. 13 illustrates by examples the application of this classification.

Wurnig (1954), from the same clinic in Vienna, recently reviewed 158 patients, who had left the hospital at least three years previously after sur- 


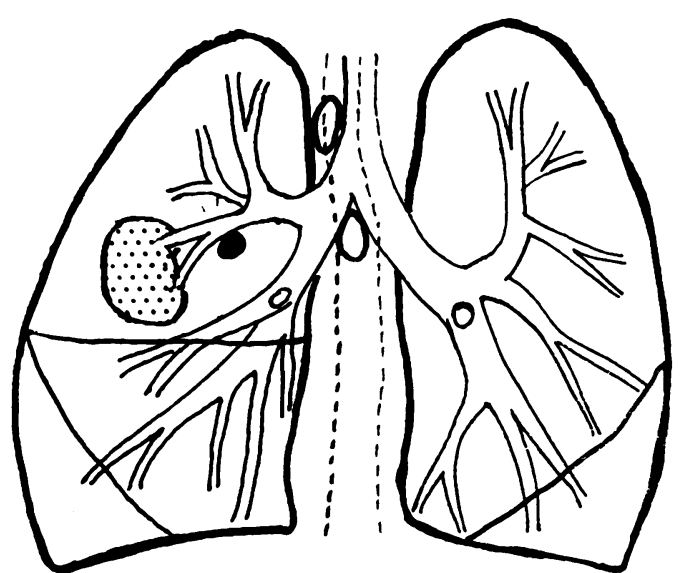

$A_{1}$ case

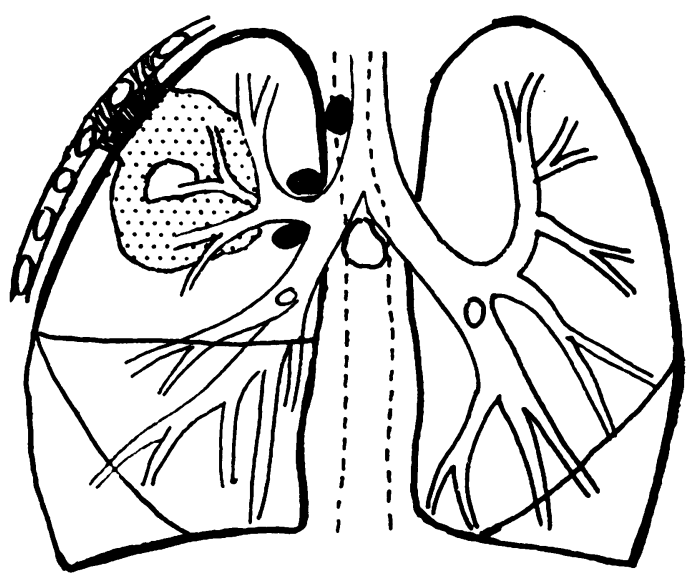

$\mathrm{C}_{3}$ case

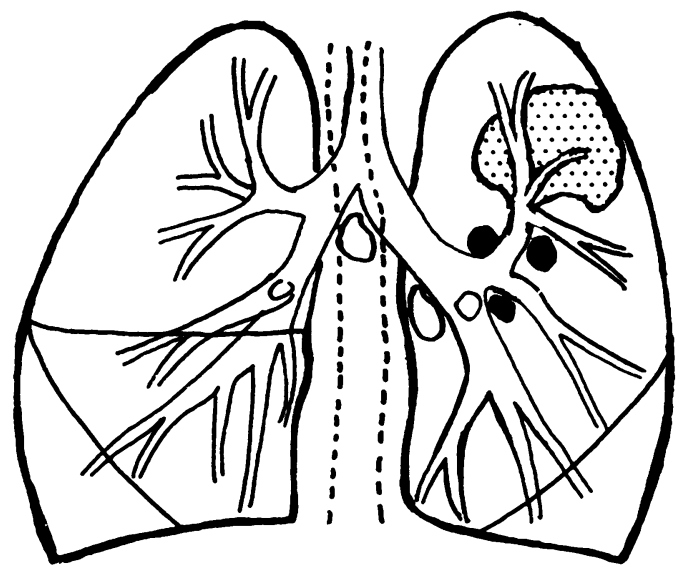

$B_{2}$ case

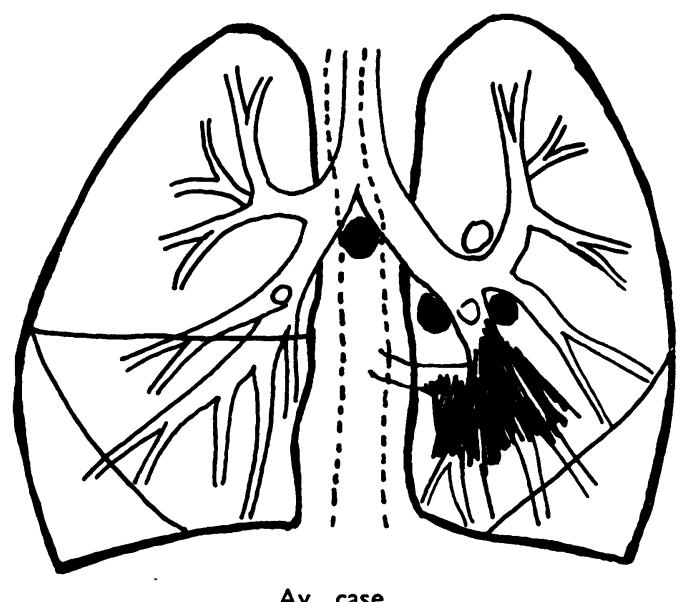

$\mathrm{Av}_{3}$ case

FIG. 13.-Illustration by examples of the application of Salzer's modified classification.

gical resection for bronchogenic carcinoma. They all had been classified according to Salzer's scheme. During the first 18 months after operation there was a rapid decline in the percentage of survivors. After this period $51 \%$ of the A cases were dead as compared with $83 \%$ of the $C$ cases, while the B cases took up an intermediate position. After this initial drop in the percentage of survivors in the first 18 months, the percentage curve levels out, to become almost horizontal after four years. The interesting facts are that after four years 35\% of survivors are found in the A category with no lymph nodes involved, while only $18 \%$ of the A cases with intrapulmonary or hilar lymph node metastases are alive. Among the $B$ cases there are only $15 \%$ of patients living and this figure approaches the percentage of the few $\mathrm{C}$ survivors, of whom only $12 \%$ are alive. This seems to sug- gest that not only is this classification valid where prognosis is concerned, but that it also serves as a yardstick when assessing various forms of treatment. Furthermore, his investigation suggests that it is justifiable to retain the B category as a separate entity.

\section{Analysis of the Present Material According to Salzer's Classification}

The 100 cases presented here have therefore been analysed according to the above proposed classification (Table VI). The following facts become apparent on analysis. In $60 \%$ of the undifferentiated cases the mediastinal lymph nodes were infiltrated with growth (column 3 ) while this happened in only $34 \%$ of the squamous cell carcinomata. Every one of the three oat cell carcinomata showed mediastinal lymph node involve- 
TABLE VI

100 CASES ANALYSED ACCORDING TO SUGGESTED CLASSIFICATION

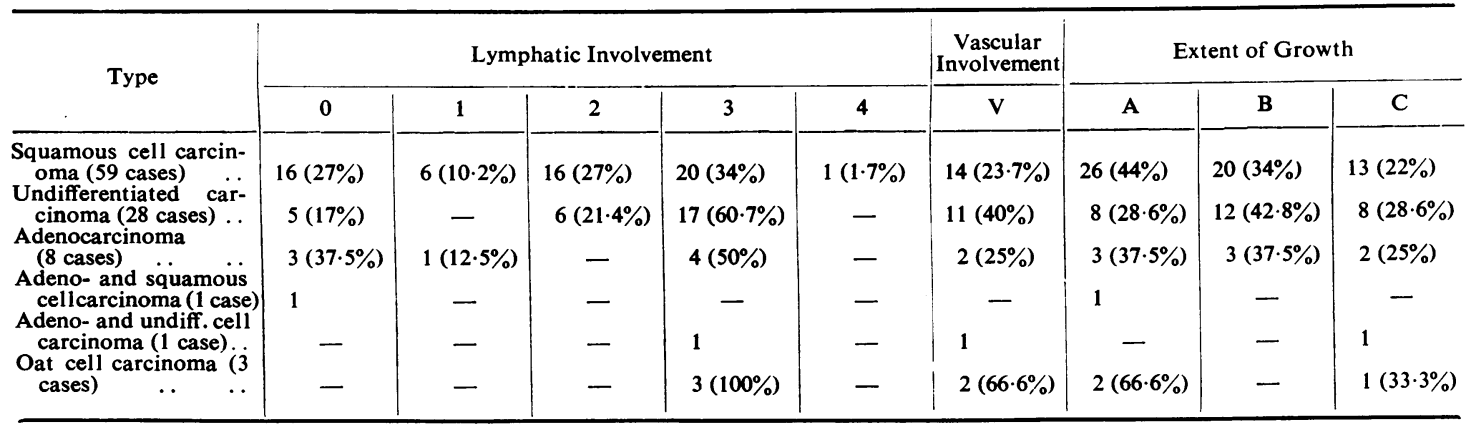

ment. On the other hand, $37.2 \%$ of the squamous growths showed either no lymphatic metastases or only infiltration of the intrapulmonary nodes (columns 0 and 1) compared with $17 \%$ of the undifferentiated group. The difference between the two types is also shown in the vascular involvement, viz., in $40 \%$ of the undifferentiated neoplasms venous intimal invasion was demonstrated, while this was only possible in $23.7 \%$ of the squamous growths. It was surprising to find that the difference between the two types, where the extent of the growth was concerned, was not so striking. The number of adenocarcinomata is too small for any conclusions to be drawn.

\section{Comparison between Peripheral and Central TUMOURS}

It was also thought that it might be interesting to analyse these cases from the point of view of peripheral tumours as compared with central growths. Opinions still seem to be divided as to which type carries the better prognosis. Rabin and Neuhof (1934) were the first to make a distinction between the "peripheral, circumscribed tumours" and the "central non-circumscribed, infiltrating type of growths." They maintained that the former carried a better prognosis than the central type, because of moderate or late lymph node metastases. In the same issue of the Journal of Thoracic Surgery, a paper by Tuttle and Womack (1934), however, comes to the opposite conclusion. They classed "peripheral $\rightarrow$ tumours" as those situated distal to the first bifurcation of the major bronchus, and these carry a worse prognosis than their "major bronchus tumours." The definition of peripheral growths in this investigation was: "Tumours invisible on bronchoscopy, confirmed later by dissection of the specimen." There were, in all, 41 peripheral tumours to 59 central growths. Among the central growths there were two cases where the pre-operative bronchoscopy was negative, but where the dissection later showed that the growth ought to have been seen.

Table VII shows the relationship between the site of the growth and the histological type. The

TABLE VII

RELATION BETWEEN SITE OF GROWTH AND HISTOLOGICAL TYPE

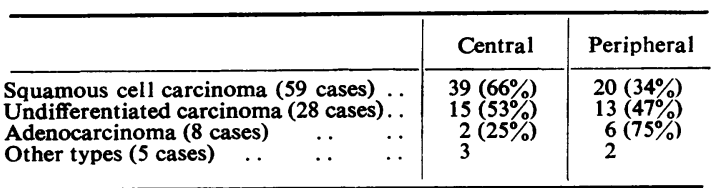

distribution agrees roughly with the findings of other authors (Wiklund, 1951; Walter and Pryce, 1955), especially the observation that adenocarcinomata are more often peripheral tumours, while the squamous cell carcinomata tend to be more centrally situated.

TABLE VIII

ANALYSIS OF TYPES ACCORDING TO SUGGESTED CLASSIFICATION

\begin{tabular}{|c|c|c|c|c|c|c|c|c|c|}
\hline \multirow{2}{*}{ Type } & \multicolumn{5}{|c|}{ Lymphatic Involvement } & \multirow{2}{*}{$\frac{\begin{array}{c}\text { Vascular } \\
\text { Involvement }\end{array}}{\mathrm{V}}$} & \multicolumn{3}{|c|}{ Extent of Growth } \\
\hline & 0 & 1 & 2 & 3 & 4 & & $\mathbf{A}$ & B & C \\
\hline $\begin{array}{l}59 \text { central tumours .. } \\
41 \text { peripheral tumours }\end{array}$ & $\begin{array}{l}13(22 \%) \\
12(29 \cdot 3 \%)\end{array}$ & $\begin{array}{l}3(5 \cdot 1 \%) \\
5(12 \cdot 2 \%)\end{array}$ & $\begin{array}{r}16(27 \cdot 1 \%) \\
5(12 \cdot 2 \%)\end{array}$ & $\begin{array}{l}27(45 \cdot 8 \%) \\
18(43.9 \%)\end{array}$ & $1(\overline{2 \cdot 4} \%)$ & $\begin{array}{l}21(35 \cdot 7 \%) \\
10(24 \cdot 4 \%)\end{array}$ & $\begin{array}{l}24(40 \cdot 8 \%) \\
17(41 \cdot 5 \%)\end{array}$ & $\begin{array}{l}19(32.1 \%) \\
15(36.6 \%)\end{array}$ & $\begin{array}{r}16(27 \cdot 1 \%) \\
9(21 \cdot 9 \%)\end{array}$ \\
\hline
\end{tabular}


Table VIII shows the analysis of the two types according to the suggested classification. According to these findings there is statistically no difference between the two types where the extent of the growth and the lymphatic involvement are concerned. The demonstrable vascular involvement is slightly higher with central growths. This may, however, be due to the difficulty of demonstrating vascular invasion in the small peripheral vessels.

\section{SUMMARY}

A hundred* specimens of lungs, resected for bronchogenic carcinoma, have been dissected to determine the site and extent of the growth, and vascular and lymphatic involvement.

The findings and conclusions drawn from this investigation are:

(1) The incidence of lymph node involvement in the 100 cases was $75 \%$.

(2) There is a constant lobar lymphatic drainage, which is described in detail.

(3) Lobectomy for bronchogenic carcinoma, where technically feasible, is a sound procedure from the pathological point of view.

(4) A comparison of lymphatic invasion rates between the different lobes shows that tumours of the lower lobes on each side have a greater tendency to metastasize than those of the upper lobes, and that if the tumour transgresses the fissure the invasion rate rises significantly.

(5) A surgical-pathological classification, as has been established for cancer at other sites, is proposed. It records the extent of growth, the lymph node infiltration, and the vascular involvement. The purpose of the scheme is to allow comparisons to be made between different forms of treatment, study the different behaviour of the histological types of growths, and assess in future the prognosis of each case.

(6) With the aid of this classification the 100 resected cases have been analysed and the following findings ascertained:

(a) Of the squamous carcinomata $37.2 \%$ showed either no lymphatic involvement or only infiltration of the intrapulmonary nodes as compared with $17 \%$ of the undifferentiated carcinomata.

* Since this paper was submitted a further 75 lungs have been dissected and classified, making 175 lungs in all. The results obtained from these further dissections fully substantiate the facts and statements set out in this paper. (b) The mediastinal lymph node involvement of the two types was $34 \%$ as compared with $60.7 \%$ (squamous carcinoma to undifferentiated carcinoma).

(c) There was also a difference in the incidence of vascular involvement $23.7 \%$ to $40 \%$ (squamous to undifferentiated carcinomata).

(d) There was no significant difference between the histological types where the extent of growth was concerned.

(e) The peripheral tumours behave in exactly the same way as the central tumours where the extent of the growth and the lymph node involvement are concerned. The vascular infiltration is only slightly more frequent in the central growths, but this may be due to difficulty in demonstrating invasion in the small peripheral vessels, which is thought to occur more frequently, for reasons stated.

(7) The observation that squamous cell carcinomata are more often centrally than peripherally located (66\% to $34 \%)$ and the adenocarcinomata are in the majority of cases peripheral tumours agrees with the observations by other authors.

In conclusion I would like to thank the surgical staff of the London Chest Hospital for their encouragement, and especially Dr. K. F. W. Hinson for much help and advice. To him and his laboratory technician, Mr. V. Jones, this investigation meant a considerable increase of work, and I am truly grateful to both of them. My thanks are also due to Miss Y. Reeves for secretarial work.

\section{REFERENCES}

Aylwin, J. A. (1951). Thorax, 6, 250.

Bignall, J. R., and Moon, A. J. (1955), Ibid., 10, 183.

Borrie, J. (1952). Ann. roy. Coll. Surg., 10, 165.

Brock, R., and Whytehead, L. L. (1955). Brit. J. Surg., 43, 8.

Churchill, E. D., Sweet, R. H., Soutter, L., and Scannell, J. G. (1950). J. thorac. Surg., $20,349$.

Higginson, J. F. (1953). Ibid., 25, 582.

McCort, J. J., and Robbins, L. L. (1951). Radiology, 57, 339.

Ninfo, G. (1950). Policlinico, Sez. prat., 57, 1213.

Ochsner, A., Dixon, J. L., and DeBakey, M. (1945). Clinics, 3, 1187.

Rabin, C. B., and Neuhof, H. (1934). J. thorac. Surg., 4, 147.

Rienhoff, W. F. (1947). Ann. Surg., 125, 541.

Rouvi ̀̀re, H. (1932). Anatomie des Lymphatiques de l'Homme. Masson, Paris.

Salzer, G. (1951). Wien. med. Wschr., 101, 102

- Wenzl, M., Jenny, R. H., and Stangl, A. (1952). Das Bronchuscarcinom. Śpringer Verlag, Wien.

Simpson, S. L. (1929). Quart. J. Med., 22, 413.

Tuttle, W. C., and Womack, N. A. (1934). J. thorac. Surg., 4, 125.

Walter, J. B., and Pryce, D. M. (1955). Thorax, 10, 117.

Warren, M. F., and Drinker, C. K. (1942). Amer. J. Physiol., 136, 207.

Weinberg, J. A. (1951). J. thorac. Surg., 22, 517.

Wiklund, T. (1951). Acta chir. scand., Suppl. 162.

Willis, R. A. (1953). Pathology of Tumours, 2nd ed. Butterworth, London.

Wurnig, P. (1954). Thorax-Chirurgie, 2, 281. 